\title{
Metformin upregulates E-cadherin and inhibits B16F10 cell motility, invasion and migration
}

\author{
GUANZHAO LIANG, MINGLEI DING, HAITAO LU, NA CAO, YANDONG NIU, YANG GAO and JIE LU
}

Department of Dermatology, The Affiliated Hospital of Chengde Medical College, Chengde, Hebei 067000, P.R. China

Received August 28, 2014; Accepted May 20, 2015

DOI: $10.3892 / 01.2015 .3475$

\begin{abstract}
Malignant melanoma is a highly metastatic cancer, and has a poor prognosis once metastasis has occurred. E-cadherin downregulation is associated with a poorer prognosis in various types of cancer, including lung, ovarian, cervical and prostate. In the majority of cancer cell lines, E-cadherin upregulation inhibits cell motility, migration and invasiveness, and reduces tumor metastasis in in vivo models. In the present study, the inhibitory effects of metformin on the motility, invasion and migration of the B16F10 murine melanoma cell line, and the possible molecular mechanisms underlying this effect were investigated. B16F10 cells were treated with various concentrations of metformin for $24 \mathrm{~h}$ and their motility, migration and invasion were tested using a wound-healing assay, a migration assay and a matrigel invasion assay, respectively. Furthermore, the expression of E-cadherin was measured by immunocytochemistry, western blotting and reverse transcription-quantitative polymerase chain reaction. The results showed that metformin effectively upregulated the expression of E-cadherin, and inhibited B16F10 cell motility, migration and invasion, in a dose-dependent manner. This suggested that the inhibition of motility, migration and invasion of B16F10 cells by metformin may be associated with the upregulation of E-cadherin expression, indicating that metformin may have a role in the treatment of melanoma.
\end{abstract}

\section{Introduction}

Malignant melanoma is a potentially fatal form of skin cancer, with a strong capacity for invasion and metastasis, and high rates of recurrence and mortality $(1,2)$, as well as a limited response to currently available treatments, such as chemotherapy and radiotherapy. The incidence and rate of

Correspondence to: Professor Jie Lu, Department of Dermatology, The Affiliated Hospital of Chengde Medical College, 36 Nanyingzidajie, Chengde, Hebei 067000, P.R. China

E-mail: chengdejiel@163.com

Key words: metformin, melanoma, E-cadherin, invasion, migration, motility mortality of malignant melanoma have been increasing in the USA and Europe faster than any those of other type of cancer (3). The median survival following the onset of distant metastases is just 6-9 months and the five-year survival rate is $<5 \%$ (4).

The progression of melanoma is necessarily a complex multistep process, as a cancer cell must acquire the ability to survive under attachment-free conditions; migrate and invade through the surrounding stroma; intravasate into the vascular system; extravasate into, and subsequently endure a disadvantageous distant environment; adhere to the local tissue; and proliferate (5). The initiation of metastasis has been attributed to the process of epithelial to mesenchymal transition (EMT), in which a differentiated tumor cell transforms into a more invasive, motile and resistant cell (6). EMT is characterized as a downregulation of epithelial markers, in particular E-cadherin, and an upregulation of mesenchymal markers, particularly vimentin or fibronectin (7). E-cadherin is a key mediator of cell-cell adhesions in epithelial tissues, and loss of E-cadherin may enhance the invasive and metastatic behavior of melanoma cells (8). During malignant transformation, the transition from radial growth phase (RGP) to vertical growth phase (VGP) is characterized by reduced E-cadherin expression that results in the loss of keratinocyte-mediated growth and motility control (9).

Metformin, a biguanide, is the most widely prescribed drug for type 2 diabetes, worldwide (10). Metformin exerts its effects by repressing hepatic gluconeogenesis, and increasing insulin sensitivity and glucose uptake. Studies have indicated that metformin efficiently suppresses the growth of various tumors, such as prostate carcinoma, and breast, lung and pancreatic cancer $(11,12)$, which is in accordance with the results of a retrospective epidemiological study, showing a reduction in cancer risk in patients with diabetes who were receiving metformin (13). Furthermore, a number of studies have reported that metformin inhibits melanoma cell proliferation (14-17).

Although, Cerezo et al (18) reported that metformin inhibited melanoma invasion, and that this was associated with reduced expression of proteins involved in EMT, such as fibronectin, N-cadherin, Vimentin and SPARC, the effect of metformin on the expression of E-cadherin was not demonstrated. In the present study, the effect of metformin on the protein and mRNA expression of E-cadherin was measured, in addition to the impact of metformin on the migration and invasion of B16F10 melanoma cells. 


\section{Materials and methods}

Chemicals. Metformin was obtained from Sigma Chemical Co. (St. Louis, MO,USA). RPMI 1640 medium was obtained from Gibco BRL (Gaithersburg, MD, USA). Penicillin and streptomycin were obtained from North China Pharmaceutical Group Corp (Shijiazhuang, China)). TRIzol reagent and crystal violet were obtained from Solarbio (Beijing, China). 0.05\% trypsine-EDTA and fetal bovine serum (FBS) were obtained from Invitrogen Life Technologies (Carlsbad, CA, USA).

Cell culture. The B16F10 melanoma cell line was obtained from KeyGen Biotech (Nanjing, China) and cultured in RPMI 1640 medium, containing 10\% FBS, $100 \mathrm{~g} / \mathrm{ml}$ streptomycin and $100 \mathrm{U} / \mathrm{ml}$ penicillin at $37^{\circ} \mathrm{C}$ in a humidified atmosphere of $5 \% \mathrm{CO}_{2}$. The $\mathrm{B} 16 \mathrm{~F} 10$ cells were cultured in a 6-well plate $\left(1 \times 10^{6}\right.$ cells/well) for RNA isolation and western blot analysis, and incubated in a 96-well flat-bottom plate $\left(1 \times 10^{4}\right.$ cells/well) for cell viability analysis. Trypsin/EDTA was used to prepare cells for the experiments and cells were rested for $24 \mathrm{~h}$ in FBS-free medium prior to treatment with the indicated concentrations of metformin (specified for each experiment) for $24 \mathrm{~h}$.

Analysis of cell proliferation. A 3-(4,5-dimethylthiazol-2-yl)-2,5-diphenyl-tetrazolium bromide (MTT) assay was used to determine whether metformin altered cell proliferation. Cells were seeded at a density of $1 \times 10^{4}$ cells/well in a 96-well plate. The cells were treated with metformin at various concentrations $(0,1,2.5$ or $5 \mathrm{mM})$ for $24 \mathrm{~h}$. Following incubation, cells were incubated with the MTT solution (Sigma-Aldrich, St. Louis, MO, USA) at a final concentration of $0.5 \mathrm{mg} / \mathrm{ml}$ for $4 \mathrm{~h}, 37^{\circ} \mathrm{C}$ in a humidified atmosphere of $5 \%$ $\mathrm{CO}_{2}$. Subsequently, the cells were lysed in dimethyl sulfoxide and the absorbance at $570 \mathrm{~nm}$ was measured using a microplate reader (Bio-Rad Laboratories, Hercules, CA, USA).

Wound healing assay. The wound healing assay was conducted as described previously, by Liang et al (19). B16F10 cells were seeded in a 6-well plate and grown to confluent monolayers. Next, the B16F10 cells were cultured in RPMI-1640 medium without FBS for $12 \mathrm{~h}$. A $200 \mu \mathrm{l}$ pipette tip was drawn across the center of the well in order to produce a wound area and washed twice with serum-free RPMI 1640 to remove loose cells. The cells were then treated with a medium containing different concentrations of metformin $(2.5$ or $5 \mathrm{mM})$ and $1 \%$ FBS (1\% FBS permits cell survival but not cell proliferation). Subsequently, images of the wound healing process were photographed digitally (x100) at 0,12 and $24 \mathrm{~h}$. Each value was derived from three randomly selected fields.

Matrigel invasion assay. B16F10 melanoma cells were incubated in RPMI 1640 with 10\% FBS and collected by trypsinization. A cell suspension $\left(200 \mu \mathrm{l}\right.$ of $5 \times 10^{5}$ cells $/ \mathrm{ml}$ with $1 \%$ FBS), containing various concentrations of metformin (1, 2.5 or $5 \mathrm{mM}$ ) was added into the inner cup of a 24-well Transwell chamber, which had been coated with $50 \mu 1$ of Matrigel ${ }^{\mathrm{TM}}$ (BD Biosciences, Franklin Lakes, NJ, USA; 1:4 dilution in serum-free medium). The medium, supplemented with $10 \%$ serum, was added to the outer cup. After 24 h, non-invading cells were removed from the upper surface by gently rubbing with a cotton-tipped swab. Cells that had migrated through the Matrigel and the $8-\mu \mathrm{m}$ pore membrane, were fixed with $3 \%$ paraformaldehyde for $15 \mathrm{~min}$, stained with crystal violet for $30 \mathrm{~min}$ and then counted in five random microscopic fields of the lower filter surface. Each experiment was performed in triplicate.

Migration assay. A 24-well Transwell chamber (Corning Life Sciences, Corning, New York, NY, USA) with an $8-\mu \mathrm{m}$-pore PET membrane, was used to conduct the migration assay. The lower chamber was filled with $600 \mu 1$ RPMI 1640, containing $10 \%$ FBS. Subsequently, $200 \mu 1$ B16F10 melanoma cells suspension $\left(5 \times 10^{5}\right.$ cells $/ \mathrm{ml}$ with $\left.1 \% \mathrm{FBS}\right)$, containing various concentrations of metformin $(1,2.5$ or $5 \mathrm{mM})$ were added into the insert. The cells were allowed to migrate at $37^{\circ} \mathrm{C}$ with $5 \% \mathrm{CO}_{2}$ over $24 \mathrm{~h}$. Non-migrating cells were removed from the upper surface of the inserts by gently rubbing with a cotton-tipped swab. Cells that had migrated to the lower surface of the inserts were washed, fixed and stained with crystal violet. Quantitative OD at a wavelength of $570 \mathrm{~nm}$ of crystal violet staining dissolved in 33\% acetic acid, represented migrated cells. Experiments were performed at least in triplicate.

Immunocytochemistry. Immunocytochemistry was performed in order to determine the expression of E-cadherin in B16F10 melanoma cells. Briefly, sterilized slides were placed into a 24-well flat-bottomed plate. B16F10 melanoma cells with $1 \%$ FBS, containing various concentrations of metformin $(0,1,2.5$ and $5 \mathrm{mM})$, were added into the 24-well plate ( $1 \times 10^{5}$ cells/well); the total volume of each well was $500 \mathrm{ml}$. Following a $24 \mathrm{~h}$ incubation, slides were fixed with $3 \%$ paraformaldehyde for $15 \mathrm{~min}$ and incubated in $3 \%$ hydrogen peroxide to inhibit endogenous peroxidase activity. After blocking with 5\% normal goat serum, a rabbit polyclonal primary antibody against E-cadherin (cat. no. ZS-7870; ZSGB-BIO, Beijing, China) was used at a 1:50 dilution and incubated overnight at $4^{\circ} \mathrm{C}$. Subsequently, a polyclonal peroxidase-conjugated goat anti-rabbit antibody (cat. no. ZDR-5306, ZSGB-BIO) was added at a 1:500 dilution and incubated for $1 \mathrm{~h}$ at room temperature $\left(25^{\circ} \mathrm{C}\right)$. Finally, slides were developed in a substrate solution of DAB (Vector Laboratories, Burlingame, CA, USA) and counter-stained with hematoxylin. All Slides were examined and photographed under a light microscope.

Reverse transcription-quantitative polymerase chain reaction (RT-qPCR) analysis. Total RNA was extracted from B16F10 cells that had been treated with various concentrations of metformin $(0,1,2.5$ or $5 \mathrm{mM})$ for $24 \mathrm{~h}$. An RNA extraction kit (Solarbio,) was used for the extraction of total RNA. The concentration of total RNA was quantified by measuring the optical density (OD) at $260 \mathrm{~nm}$ and RNA integrity was confirmed using denaturing agarose gel electrophoresis. Reverse transcription was conducted using a PrimeScript ${ }^{\mathrm{TM}}$ RT Master Mix kit (Takara, Dalian, China), according to the manufacturer's instructions. RT-qPCR was conducted in the Stratagene Mx3000P (Stratagene, La Jolla, CA, USA) using a SYBR ${ }^{\circledR}$ Premix DimerEraser ${ }^{\mathrm{TM}}$ kit (Takara). By detecting 


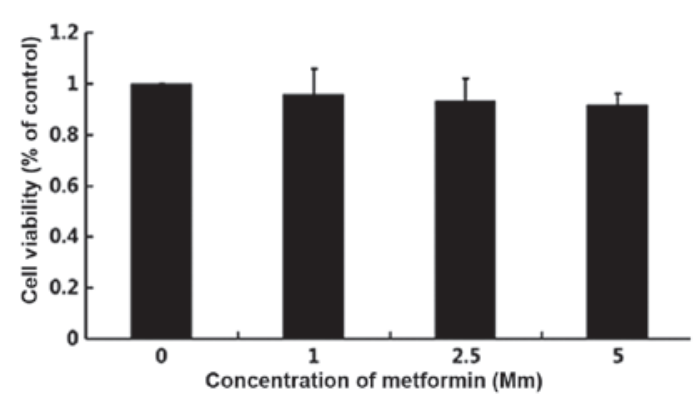

Figure 1. Effect of metformin on B16F10 melanoma cell proliferation. Cells were treated with various concentrations $(0,1,2.5$ and $5 \mathrm{mM})$ of metformin for $24 \mathrm{~h}$. An MTT assay was used to estimate cell proliferation. Data are presented as the mean \pm standard deviation from three experiments. All $\mathrm{P}>0.05$ vs. control

the increase in the level of the reporter dye (SYBR), the PCR product was monitored continuously during the reaction using MxProTMQPCR software (Stratagene, La Jolla, CA, USA). The cycling conditions were in two stages. An initial denaturation step at $95^{\circ} \mathrm{C}$ for $30 \mathrm{sec}$ for one cycle. The PCR amplification step was 40 cycles of $95^{\circ} \mathrm{C}$ for $30 \mathrm{sec}, 58^{\circ} \mathrm{C}$ for $30 \mathrm{sec}$ and $72^{\circ} \mathrm{C}$ for $30 \mathrm{sec}$. The expression of E-cadherin mRNA in the treated cells was compared to that in the control cells at each timepoint, using the comparative cycle threshold (Ct) method. The following primers were used: Forward, 5'-ATTGCAAGTTCCTGCCATCCTC-3' and reverse, 5'-CACATTGTCCCGGGTATCATCA-3' for E-cadherin and forward, 5'-CATCCGTAAAGACCTCTATGCCAAC-3' and reverse, 5'-ATGGAGCCACCGATCCACA-3' for $\beta$-actin. According to the manufacturer's instructions, the quantity of each transcript was calculated and normalized to the quantity of $\beta$-actin, as an internal standard.

Western blot analysis. B16F10 melanoma cells $\left(1 \times 10^{6}\right)$ in the exponential phase of growth, were plated in a 6-well plate and treated with metformin $(0,1,2.5$ or $5 \mathrm{mM})$. Following treatment, cells were collected and washed with phosphate-buffered saline. The total protein was extracted using a RIPA lysis buffer kit (BestBio, shanghai, China), on ice for $30 \mathrm{~min}$. The lysates were collected and centrifuged at $12,000 \mathrm{xg}$ for $30 \mathrm{~min}$ at $4{ }^{\circ} \mathrm{C}$. Protein concentrations were detected using a bicinchoninic acid protein assay kit (Multisciences, Hangzhou, China). Aliquots of the lysates were boiled for $5 \mathrm{~min}$, electrophoresed on $10 \%$ SDS-PAGE gels and transferred to a PVDF membrane (Merck Millipore, Darmstadt, Germany). The membrane was blocked with $1 \% \mathrm{BSA}$ at room temperature for $1 \mathrm{~h}$ and then probed with primary polyclonal antibodies to E-cadherin at a 1:50 dilution (cat. no.ZS-7870; ZSGB-BIO) and $\beta$-actin at a 1:1,000 dilution (cat. no. sc-7210; Santa Cruz Biotechnology, Inc., Dallas, TX, USA) overnight at $4^{\circ} \mathrm{C}$, followed by incubation with the HRP-labeled goat-anti-rabbit secondary antibodies at a 1:5,000 dilution (KPL, Gaithersburg, MD, USA) for $1 \mathrm{~h}$ at $25^{\circ} \mathrm{C}$. Finally, protein bands were detected using an enhanced chemiluminescence Western blotting detection kit (Santa Cruz Biotechnology, Inc.). The bands were quantified with a Gel Doc 2000 system and Quantity One software, version 4.6 (Bio-Rad Laboratories), and expressed as a ratio of the quantity of E-cadherin to $\beta$-actin, followed by standardization, with the ratio of the normal control set as 1 .
$\mathbf{A}$

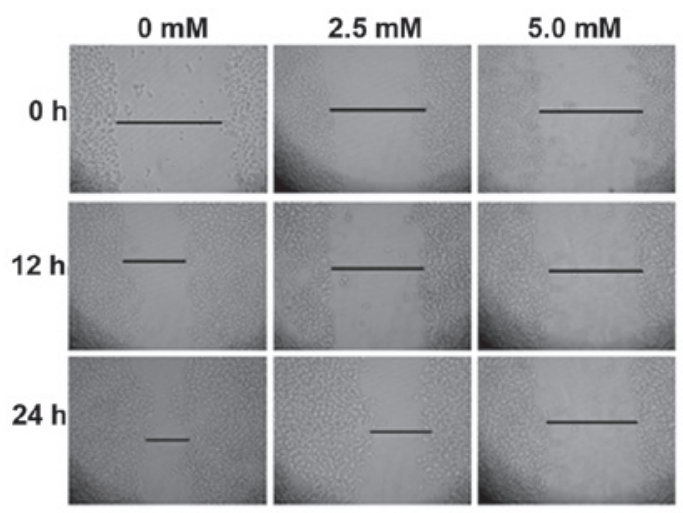

B

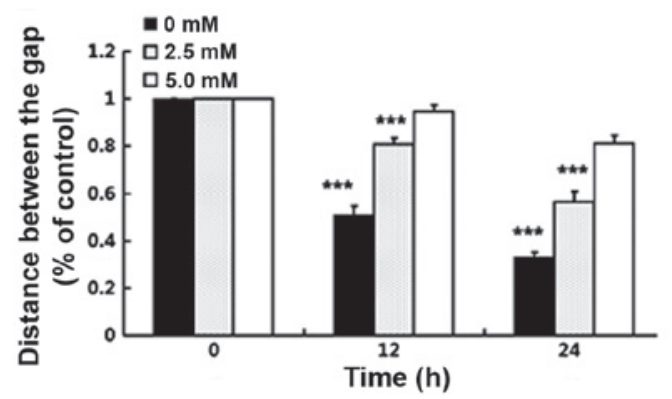

Figure 2. Metformin inhibited B16F10 melanoma cell invasion in a 'wound' repair model. (A) Microscopic appearance of wound healing processes in the control and metformin (2.5 and $5 \mathrm{mM}$ ) groups at 0,12 and $24 \mathrm{~h}$. B16F10 cells were plated in 6-well plates and grown to $80 \%$ confluence. After generating a scratch in the monolayer, cells were incubated with or without metformin. Images were captured at 0,12 and $24 \mathrm{~h}$ after wounding. Magnification, x100. (B) The area of the gap region was quantified by measuring three selected fields under the microscope. Data are expressed as a percentage of the mobility in the untreated B16F10 melanoma cells (mean \pm standard deviation), ${ }^{* * *} \mathrm{P}<0.001$ vs. the control group.

Statistical analysis. All experiments were repeated at least three times. The mean \pm standard deviation was calculated for each group, and data were analyzed using one-way analysis of variance followed by a post hoc least significant differences multiple comparison test. Statistical analysis was performed using SPSS software, version 17.0 (SPSS, Inc., Chicago, IL, USA). $\mathrm{P} \leq 0.05$ was considered to indicate a statistically significant difference.

\section{Results}

Effect of metformin on the proliferation of B16F10 melanoma cells. The cytotoxicity of metformin in the B16F10 murine melanoma cell line was evaluated by treating the cells with metformin, at concentrations of $0,1,2.5$ or $5 \mathrm{mM}$ for $24 \mathrm{~h}$. As shown in Fig. 1, no significant cytotoxicity was observed. Since metformin was not cytotoxic in B16F10 cells at $5 \mathrm{mM}$, metformin were used at concentrations of $5 \mathrm{mM}$ or lower in subsequent experiments.

Metformin inhibits B16F10 cell motility, invasion and migration. Increased cell motility is a characteristic that is associated with malignancy. The 'wound' repair model was used to evaluate the effect of metformin on the motility of B16F10 cells. As shown by the wound healing assay (Fig. 2), in the 
A
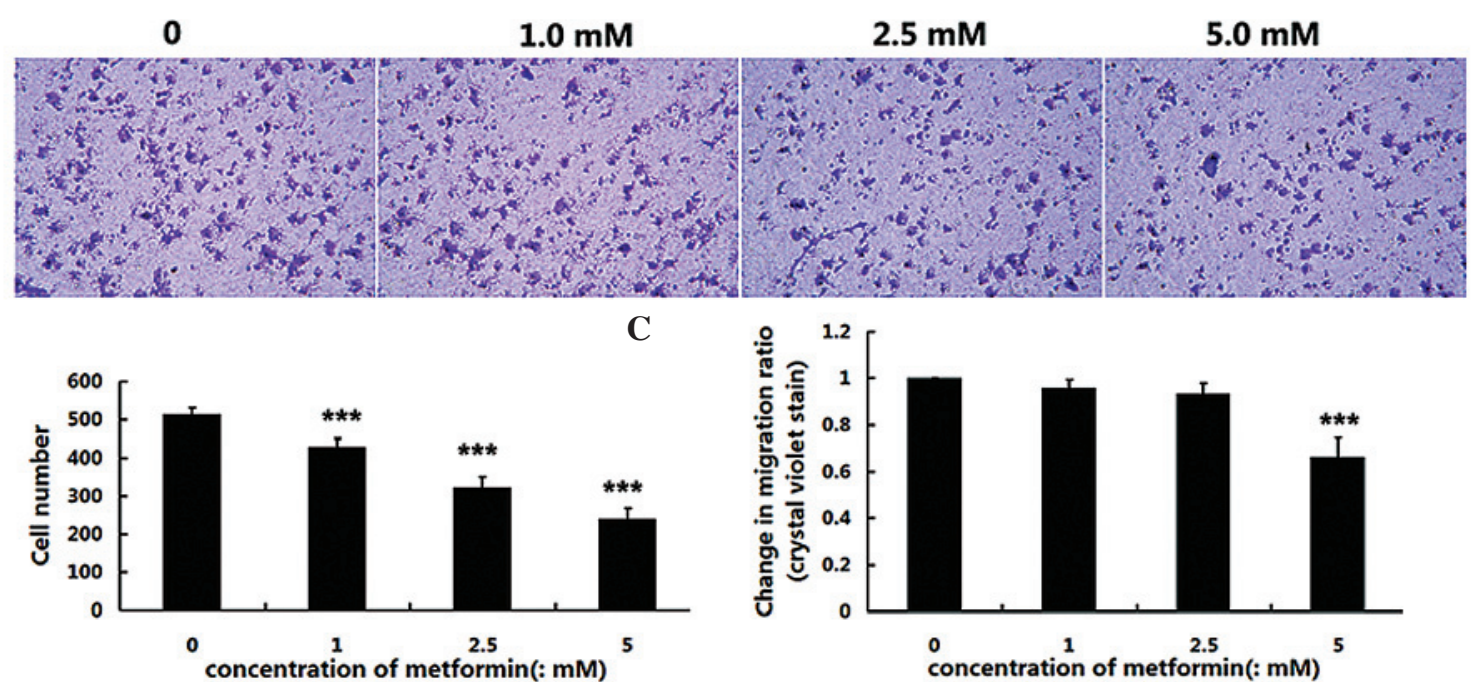

B

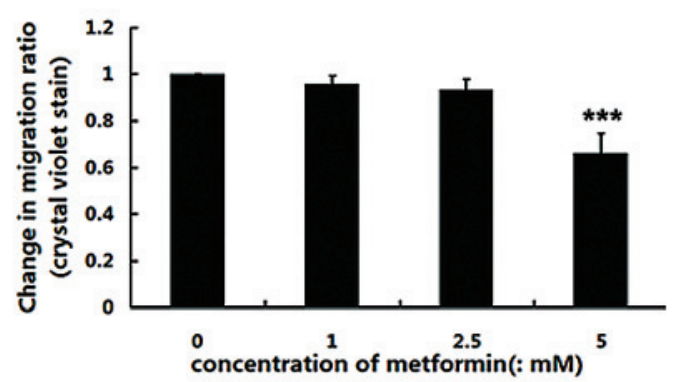

Figure 3. Metformin suppresses invasion and migration in B16F10 melanoma cells. (A) Images show the inhibitory effect of metformin (1, 2.5 and $5 \mathrm{mM}$ ) on the invasion of B16F10 melanoma cells (magnification, x200) with untreated cells forming the control group. (B) The invasion assay was quantified by measuring five selected fields under the microscope. The y-axis represents the average number of invading cells in five fields that penetrated the membrane to the lower chamber. (C) Metformin decreased B16F10 melanoma cells migration in the Transwell chamber with an 8- $\mu$ m-pore membrane. Cells treated with $1,2.5$ or $5 \mathrm{mM}$ of metformin were seeded in the upper chamber. Following $24 \mathrm{~h}$ of incubation, cells that migrated to the lower surface of the filter were fixed, stained and rinsed in $33 \%$ acetic acid. The quantitative absorbance values at a wavelength of $570 \mathrm{~nm}$, represented migrated cells. The results are presented as the mean \pm standard deviation from three experiments. ${ }^{* * *} \mathrm{P}<0.001$ vs. the control group.

A

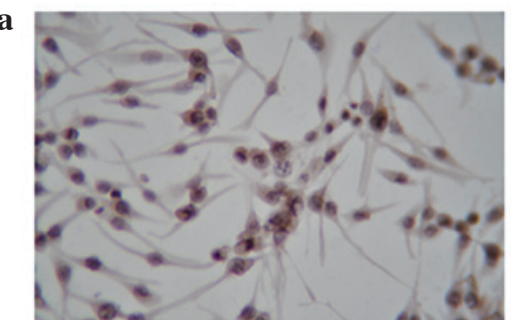

c

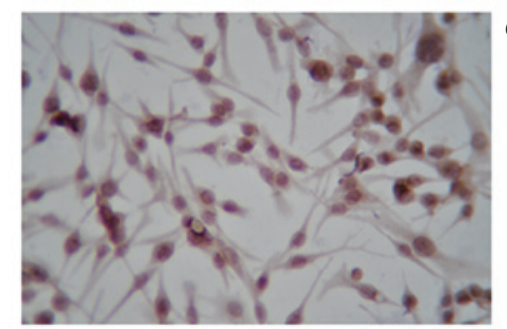

B
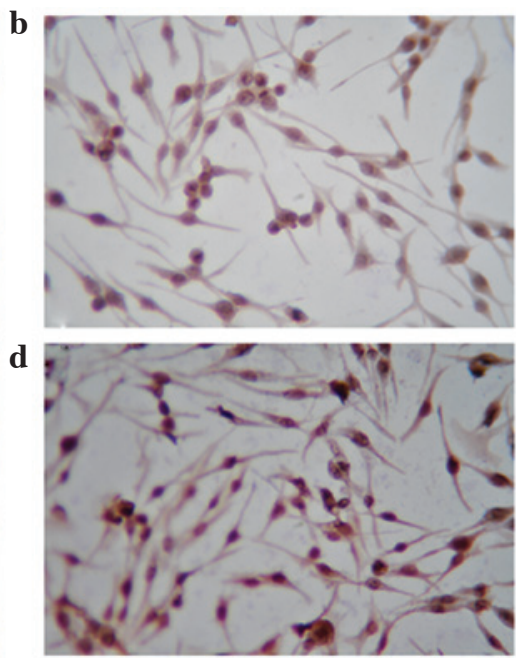

C
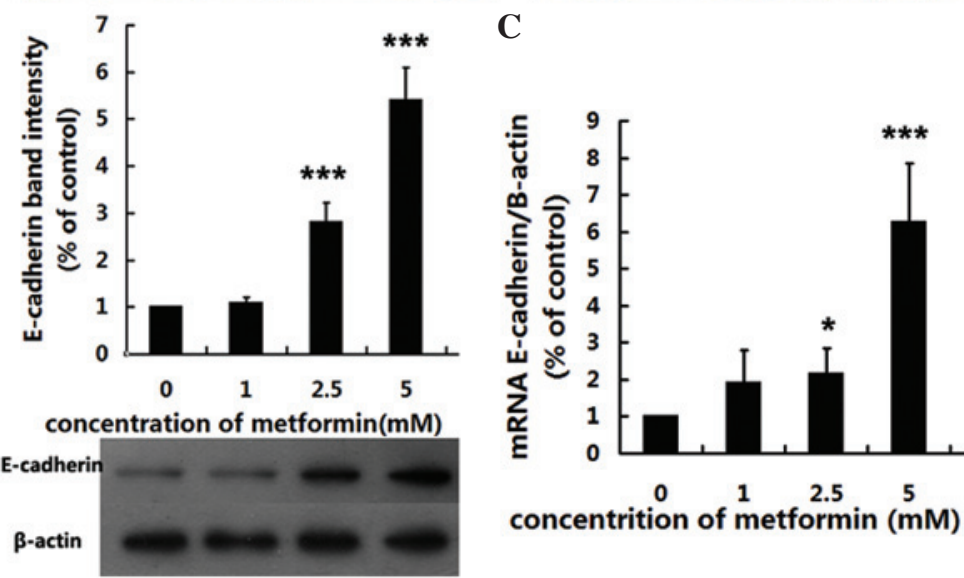

Figure 4. Gene and protein expression of E-cadherin in B16F10 melanoma cells. Cells were treated with 0, 1, 2.5 or $5 \mathrm{mM}$ metformin and incubated for $24 \mathrm{~h}$. (A) Metformin suppressed the expression of E-cadherin in B16F10 melanoma cells, as measured by immunocytochemistry (magnification, x200). (Aa) Control well without metformin. (Ab) Well containing $1 \mathrm{mM}$ metformin. (Ac) Well containing $2.5 \mathrm{mM}$ metformin. (Ad) Well containing $5 \mathrm{mM}$ metformin. (B) Western blot analyses of E-cadherin expression. $\beta$-actin was used as internal reference gene, by which to normalize the results. Densitometric quantification of the corresponding bands was performed using ImageJ 2xsoftware. (C) Reverse transcription-quantitative polymerase chain reaction analysis of E-cadherin mRNA expression. All results are presented as the mean \pm standard deviation from three experiments. ${ }^{*} \mathrm{P}<0.05$ and ${ }^{* * *} \mathrm{P}<0.001$ vs. the control group. 
group treated with metformin the rate of cell migration into the wounded area was significantly reduced compared with that in the control group (control group, 51.2 and 33\%; $2.5 \mathrm{mM}$ group, 80.8 and 56.6\%; and $5 \mathrm{mM}$ group, 94.7 and $81.6 \%$ at 12 and 24 h, respectively). Furthermore, Transwell migration and Matrigel invasion assays were used to investigate the inhibitory effects of metformin on the invasive potency of cells. The Matrigel invasion assay, a three dimensional model, showed that metformin significantly suppressed B16F10 cell invasion, while $1 \mathrm{mM}$ metformin inhibited the invasion of cells by $17 \%, 2.5 \mathrm{mM}$ inhibited invasion by $36 \%$ and $5 \mathrm{mM}$ by $47 \%$ (Fig. $3 \mathrm{~A}$ and B). In the Transwell migration assay, a significantly reduced number of migrating cells was observed when cells were treated with metformin for $24 \mathrm{~h}$, compared with that in the control group (Fig. 3C). These results suggested that non-toxic concentrations of metformin inhibit the motility, invasion and migration of B16F10 melanoma cells in a dose-dependent manner.

Metformin upregulates the expression of E-cadherin. E-cadherin is involved in the progression of cancer. The results of the immunocytochemistry experiment demonstrated that the level E-cadherin was markedly reduced in B16F10 cells following $24 \mathrm{~h}$ treatment with metformin, compared with that in the control group (Fig. 4A). Western blot analysis showed that E-cadherin expression was significantly suppressed by metformin at concentrations of 1, 2.5 and $5 \mathrm{mM}$, compared with the control group (all $\mathrm{P}<0.05$; Fig. 4B). RT-qPCR demonstrated that the level of E-cadherin mRNA in B16F10 cells was significantly reduced in the groups treated with metformin at concentrations of $1,2.5$ and $5 \mathrm{mM}$, compared with that in the control group (all $\mathrm{P}<0.05$; Fig. 4C).

\section{Discussion}

Metformin, the most widely prescribed antidiabetic drug worldwide, is well tolerated and has the major advantage of not inducing hypoglycemia. Metformin reduces hepatic glucose production through a mechanism requiring liver kinase B1, which is important in the control of the metabolic checkpoint, AMP-activated protein kinase-mammalian target of rapamycin, and neoglucogenic genes, resulting in inhibition of protein synthesis and cell proliferation (20). Observations have shown that metformin affects the regulation of tumor cell proliferation, cell-cycle regulation, apoptosis and autophagy (21). It has been reported that metformin may be effective as an anticancer drug in a variety of types of tumors, such as prostate (22), breast (23), lung (24) and pancreatic cancer (25), and melanoma (15). A retrospective epidemiological study demonstrated a reduction in cancer risk in diabetic patients treated with metformin (13). The present study focused on the effects of metformin on the invasion and migration of B16F10 melanoma cells in order to determine its effects on the metastasis of tumor cells.

Invasiveness and metastasis are the most important characteristics of malignant tumors, including melanoma. Cell adhesion is closely associated with tumor invasiveness and metastasis, and the cadherin superfamily is a group of transmembrane glycoproteins that mediate calcium-dependent homophilic intercellular adhesion. Perturbations in cadherins have been shown to be associated with the development of cancer, particularly invasion and metastasis (26). E-cadherin, expressed by the majority of normal epithelial tissues, is a prototypic member of the cadherin superfamily, and reduced expression and abnormal cellular distribution of E-cadherin have been observed to be associated with dedifferentiation and invasiveness in various human malignancies (27). Of the events occurring during the complex metastasis process, EMT, the initial step, is the most important (28). EMT promotes tumor progression, by endowing cells with migratory and invasive properties, inducing stem cell properties, suppressing apoptosis and senescence, and contributing to immunosuppression (8). Previous studies have shown a link between EMT markers in primary tumor cells and aggressive clinical behavior $(29,30)$. The majority of evidence indicates that E-cadherin is associated with EMT, and that the loss of E-cadherin may promote invasive and metastatic behavior in many types of epithelial tumors (31-33). Therefore, downregulation of E-cadherin is one of the essential hallmarks of EMT (34). During melanoma progression, the transition from RGP to VGP is characterized by reduced E-cadherin expression, accompanied by loss of keratinocyte-mediated growth and motility control (9). Tang et al (35) reported that E-cadherin expression decreased in a number of human malignant melanoma cell lines. The current study showed that motility, migration and invasion of B16F10 melanoma cells are markedly inhibited by metformin, and that E-cadherin mRNA transcription and E-cadherin protein production were upregulated by metformin in a dose-dependent manner, implying that it may be beneficial in the treatment of cancer.

Although, the E-cadherin expression in B16F10 cells, as measured by western blotting, was not entirely consistent with the results of the RT-qPCR analysis at a dose of $2.5 \mathrm{mM}$ metformin, the overall trend was similar, in that there was a dose-dependent increase in E-cadherin expression. This inconsistency may have been due to the use of different assays with different sensitivities, and different kinetics between the protein and mRNA.

In conclusion, the present data demonstrated that metformin inhibits the migration and invasion of B16F10 melanoma cells, via the upregulation of E-cadherin in a dose-dependent manner. Further in vivo studies are required to determine the inhibitory effects of metformin on tumor cell invasion. The findings in the present study indicate that metformin has the potential to be an efficient anticancer drug in the treatment of metastatic malignant melanoma.

\section{References}

1. Shore RN, Shore P, Monahan NM and Sundeen J: Serial screening for melanoma: Measures and strategies that have consistently achieved early detection and cure. J Drugs Dermatol 10: 244-252, 2011.

2. Boyle GM: Therapy for metastatic melanoma: An overview and update. Expert Rev Anticancer Ther 11: 725-737, 2011.

3. MacKie RM, Hauschild A and Eggermont AM: Epidemiology of invasive cutaneous melanoma. Ann Oncol 20 (Suppl 6): vi1-vi7, 2009.

4. Houghton AN and Polsky D: Focus on melanoma. Cancer Cell 2: 275-278, 2002

5. Chaffer CL and Weinberg RA: A perspective on cancer cell metastasis. Science 331: 1559-1564, 2011. 
6. Hollier BG, Evans K and Mani SA: The epithelial-to-mesenchymal transition and cancer stem cells: A coalition against cancer therapies. J Mammary Gland Biol Neoplasia 14: 29-43, 2009.

7. Zeisberg M and Neilson EG: Biomarkers for epithelial-mesenchymal transitions. J Clin Invest 119: 1429-1437, 2009.

8. Thiery JP, Acloque $\mathrm{H}$, Huang RY and Nieto MA: Epithelial-mesenchymal transitions in development and disease. Cell 139: 871-890, 2009.

9. Hsu MY, Meier FE, Nesbit M, Hsu JY, Van Belle P, Elder DE and Herlyn M: E-cadherin expression in melanoma cells restores keratinocyte-mediated growth control and down-regulates expression of invasion-related adhesion receptors. Am J Pathol 156: 1515-1525, 2000

10. Kourelis TV and Siegel RD: Metformin and cancer: New applications for an old drug. Med Oncol 29: 1314-1327, 2012.

11. Ben Sahra I, Le Marchand-brustel Y, Tanti JF and Bost F: Metformin in cancer therapy: A new perspective for an old antidiabetic drug? Mol Cancer Ther 9: 1092-1099, 2010.

12. Pollak M: Metformin and other biguanides in oncology: Advancing the research agenda. Cancer Prev Res (Phila) 3: 1060-1065, 2010.

13. Noto H, Goto A, Tsujimoto $\mathrm{T}$ and Noda M: Cancer risk in diabetic patients treated with metformin: A systematic review and meta-analysis. PLoS One 7: e33411, 2012.

14. Woodard J and Platanias LC: AMP-activated kinase (AMPK)-generated signals in malignant melanoma cell growth and survival. Biochem Biophys Res Commun 398: 135-139, 2010.

15. Janjetovic K, Harhaji-Trajkovic L, Misirkic-Marjanovic M, Vucicevic L, Stevanovic D, Zogovic N, Sumarac-Dumanovic M, Micic D and Trajkovic V: In vitro and in vivo anti-melanoma action of metformin. Eur J Pharmacol 668: 373-382, 2011.

16. Niehr F, von EE, Attar N, Guo D, Matsunaga D, Sazegar H, Ng C, Glaspy JA, Recio JA, Lo RS, et al: Combination therapy with vemurafenib (PLX4032/RG7204) and metformin in melanoma cell lines with distinct driver mutations. J Transl Med 9: 76 , 2011.

17. Tomic T, Botton T, Cerezo M, Robert G, Luciano F, Puissant A, Gounon P, Allegra M, Bertolotto C, Bereder JM, et al: Metformin inhibits melanoma development through autophagy and apoptosis mechanisms. Cell Death Dis 2: e199, 2011.

18. Cerezo M, Tichet M, Abbe P, Ohanna M, Lehraiki A, Rouaud F Allegra M, Giacchero D, Bahadoran P, Bertolotto C, et al: Metformin blocks melanoma invasion and metastasis development in AMPK/p53-dependent manner. Mol Cancer Ther 12: $1605-1615,2013$

19. Liang CC, Park AY and Guan JL: In vitro scratch assay: A convenient and inexpensive method for analysis of cell migration in vitro. Nat Protoc 2: 329-333, 2007.

20. Andújar-Plata P, Pi-Sunyer X and Laferrère B: Metformin effects revisited. Diabetes Res Clin Pract 95: 1-9, 2012.
21. Cerezo M, Tomic T, Ballotti R and Rocchi S. Is it time to test biguanide metformin in the treatment of melanoma? Pigment Cell Melanoma Res 28: 8-20, 2014.

22. Ben Sahra I, Laurent K, Loubat A, Giorgetti-Peraldi S, Colosetti P, Auberger P, Tanti JF, Le Marchand-Brustel Y and Bost F: The antidiabetic drug metformin exerts an antitumoral effect in vitro and in vivo through a decrease of cyclin D1 level. Oncogene 27: 3576-3586, 2008.

23. Zakikhani M, Dowling R, Fantus IG, Sonenberg N and Pollak M: Metformin is an AMP kinase-dependent growth inhibitor for breast cancer cells. Cancer Res 66: 10269-10273, 2006.

24. Algire C, Zakikhani M, Blouin MJ, Shuai JH and Pollak M: Metformin attenuates the stimulatory effect of a high-energy diet on in vivo LLC1 carcinoma growth. Endocr Relat Cancer 15: 833-839, 2008

25. Wang LW, Li ZS, Zou DW, Jin ZD, Gao J and Xu GM: Metformin induces apoptosis of pancreatic cancer cells. World J Gastroenterol 14: 7192-7198, 2008.

26. Takeichi M: Cadherins in cancer: Implications for invasion and metastasis. Curr Opin Cell Biol 5: 806-811, 1993.

27. Christofori G and Semb H: The role of the cell-adhesion molecule E-cadherin as a tumour-suppressor gene. Trends Biochem Sci 24: 73-76, 1999.

28. Rattan R, Ali Fehmi R and Munkarah A: Metformin: An emerging new therapeutic option for targeting cancer stem cells and metastasis. J Oncol 2012: 928127, 2012.

29. Sarrió D, Rodriguez-Pinilla SM, Hardisson D, Cano A, Moreno-Bueno G and Palacios J: Epithelial-mesenchymal transition in breast cancer relates to the basal-like phenotype. Cancer Res 68: 989-997, 2008.

30. Yang J, Mani SA, Donaher JL, Ramaswamy S, Itzykson RA, Come C, Savagner P, Gitelman I, Richardson A and Weinberg RA: Twist, a master regulator of morphogenesis, plays an essential role in tumor metastasis. Cell 117: 927-939, 2004.

31. Birchmeier W and Behrens J: Cadherin expression in carcinomas: role in the formation of cell junctions and the prevention of invasiveness. Biochim Biophys Acta 1198: 11-26, 1994.

32. Kalluri R and Weinberg RA: The basics of epithelial-mesenchymal transition. J Clin Invest 119: 1420-148, 2009.

33. Perl AK, Wilgenbus P, Dahl U, Semb H and Christofori G: A causal role for E-cadherin in the transition from adenoma to carcinoma. Nature 392: 190-193, 1998.

34. Nakamura M and Tokura Y: Epithelial-mesenchymal transition in the skin. J Dermatol Sci 61: 7-13, 2011.

35. Tang A, Eller MS, Hara M, Yaar M, Hirohashi $S$ and Gilchrest BA: E-cadherin is the major mediator of human melanocyte adhesion to keratinocytes in vitro. J Cell Sci 107: 983-992, 1994 